\title{
Identification and Characterization of Plant Genes Involved in Agrobacterium-Mediated Plant Transformation by Virus-Induced Gene Silencing
}

\author{
Ajith Anand, ${ }^{1}$ Zarir Vaghchhipawala, ${ }^{1}$ Choong-Min Ryu, ${ }^{1}$ Li Kang, ${ }^{1}$ Keri Wang, ${ }^{1}$ Olga del-Pozo, ${ }^{2}$ \\ Gregory B. Martin, ${ }^{2,3}$ and Kirankumar S. Mysore ${ }^{1}$ \\ ${ }^{1}$ Plant Biology Division, Samuel Roberts Noble Foundation, Ardmore, OK 73402, U.S.A.; ${ }^{2}$ Boyce Thompson Institute for \\ Plant Research, Ithaca, NY 14853, U.S.A.; ${ }^{3}$ Department of Plant Pathology, Cornell University, Ithaca, NY 14853, U.S.A.
}

Submitted 20 April 2006. Accepted 31 July 2006.

Genetic transformation of plant cells by Agrobacterium tumefaciens represents a unique case of trans-kingdom sex requiring the involvement of both bacterial virulence proteins and plant-encoded proteins. We have developed in planta and leaf-disk assays in Nicotiana benthamiana for identifying plant genes involved in Agrobacterium-mediated plant transformation using virus-induced gene silencing (VIGS) as a genomics tool. VIGS was used to validate the role of several genes that are either known or speculated to be involved in Agrobacterium-mediated plant transformation. We showed the involvement of a nodulin-like protein and an alpha-expansin protein ( $\alpha$-Exp) during Agrobacterium infection. Our data suggest that $\alpha-\operatorname{Exp}$ is involved during early events of Agrobacterium-mediated transformation but not required for attaching $A$. tumefaciens. By employing the combination of the VIGS-mediated forward genetics approach and an in planta tumorigenesis assay, we identified 21 ACG (altered crown gall) genes that, when silenced, produced altered crown gall phenotypes upon infection with a tumorigenic strain of $A$. tumefaciens. One of the plant genes identified from the screening, Histone $\mathrm{H3}(\mathrm{H3})$, was further characterized for its biological role in Agrobacterium-mediated plant transformation. We provide evidence for the role of $\mathrm{H3}$ in transfer DNA integration. The data presented here suggest that the VIGS-based approach to identify and characterize plant genes involved in genetic transformation of plant cells by $A$. tumefaciens is simple, rapid, and robust and complements other currently used approaches.

Additional keywords: functional genomics, Tobacco rattle virus.

Agrobacterium tumefaciens, known for its natural capability of transforming plants, has found extensive application in agri-

Corresponding author: K. S. Mysore: Fax: +1.580.224.6692; Telephone: +1.580.224.6740; E-mail: ksmysore@noble.org

Current address for C.-M. Ryu: Korea Research Institute of Bioscience \& Biotechnology (KRIBB), 52 Oun-dong, Yusong-gu, Daejon, 305-333, South Korea.

Current address for O. del-Pozo: Instituto de Bioquímica Vegetal y Fotosíntesis, Universidad de Sevilla-CSIC, Sevilla 41092, Spain.

* The $\boldsymbol{e}$-Xtra logo stands for "electronic extra" and indicates the HTML abstract available on-line contains supplemental material not included in the print edition. Further research methods and results are provided on-line as well as four supplemental figures and three tables. cultural biotechnology. Apart from genetic transformation of plants, the bacterium can also transform many other life-forms, including prokaryotes (Kelly and Kado 2002), fungi (Bundock et al. 1995; de Groot et al. 1998; Piers et al. 1996; Rho et al. 2001), and human cells (Kunik et al. 2001). This unique ability of A. tumefaciens to genetically transform many life forms has attracted the curiosity of researchers, leading to a better understanding of the underlying processes involved in this unique interkingdom DNA transfer (Anand and Mysore 2005; Gelvin 2003a; Tzfira and Citovsky 2002).

A. tumefaciens is a soil-borne phytopathogen that causes crown gall disease in plants. Upon infection by A. tumefaciens, a specific region of the bacterial tumor-inducing plasmid (pTi), known as the transfer DNA (T-DNA), is transferred to the plant cell and is integrated into the host genome. The processing and transport of T-DNA is governed by bacterial proteins encoded by the chromosomal (chv) and virulence (vir) genes (Gelvin 2000, 2003a; Tzfira and Citovsky 2002; Zhu et al. 2000). A significant understanding of the biological functions of many of the Agrobacterium proteins involved in the initiation, production, and transport of T-DNA has been established. A. tumefaciens uses a type IV secretion system for exporting the VirD2-T-strand complex and VirE2 protein into the plant cell separately, and they are subsequently assembled into the T-complex composed of VirD2-T-strand-VirE2. This complex has been proposed to be the form of T-DNA targeted to the nucleus (Cascales and Christie 2004; Vergunst et al. 2000). Additional virulence proteins, including VirF and VirE3, are also translocated into the plant cell during Agrobacterium infection (Schrammeijer et al. 2003; Vergunst et al. 2000). VirE3 interaction with VirE2 may facilitate the nuclear import of the T-complex (Lacroix et al. 2005). VirF carries an F-box motif that may destabilize the Tcomplex, allowing targeted proteolysis of VirE2 prior to T-DNA integration (Tzfira et al. 2004). These interactions within the plant cell are facilitated by a number of recently described host factors (Anand and Mysore 2005; Gelvin 2003a and b; Tzfira and Citovsky 2002). Additional plant factors may also mediate pathogenesis, bacterial attachment, signal transduction, nuclear import of T-DNA, targeted proteolysis, and T-DNA integration. A better understanding and characterization of these plant factors associated with Agrobacterium-mediated plant transformation will further our knowledge of the mechanism of this unique interkingdom DNA transfer.

Several approaches have been employed to identify plant factors that are required for Agrobacterium-mediated transformation, including the yeast two-hybrid system for screening Arabidopsis cDNA libraries for proteins that interact with dif- 
ferent bacterial virulence proteins, characterization of T-DNAtagged mutants that are resistant to root transformation by $A$. tumefaciens (rat mutants), and more recently, molecular characterization of differential gene expression between virulent and avirulent strains of $A$. tumefaciens (Anand and Mysore 2005; Gelvin 2003 and b; Tzfira and Citovsky 2002). However, each of these approaches has limitations, including potential lethal phenotypes arising from T-DNA insertions in essential plant genes, the inability to detect a rat phenotype due to T-DNA insertion into a $R A T$ gene within a gene family, weak rat phenotypes resulting from insertions into $3^{\prime}$ or $5^{\prime}$ untranslated regions, the detection of protein-protein interactions in the yeast two-hybrid system that are not biologically significant (Stephens and Banting 2000; von Mering et al. 2002), and the limited characterization of differentially expressed genes (Ditt et al. 2001; Veena et al. 2003). We therefore used virusinduced gene silencing (VIGS) as a functional genomics tool for identification of additional plant genes involved in Agrobacterium-mediated plant transformation and also to characterize plant genes that are speculated to be involved in the transformation process.

VIGS is an RNA-mediated posttranscriptional gene silencing mechanism that can protect plants against foreign gene invasion (Baulcombe 1999). Recently, VIGS has emerged as an efficient genomics tool for deciphering the function of genes in diverse plant species (Burch-Smith et al. 2004). For VIGS analysis, a fragment of the plant gene of interest is directly inserted into a viral vector (reverse genetics approach) or an enriched cDNA library is cloned into the viral vector (fast-forward genetics approach; Baulcombe 1999). Upon inoculation, the inserted gene is amplified by the viral replication system, spreads systemically in the infected plants, and results in the synthesis of dsRNA intermediates that trigger the RNA-mediated defense system (the RNA-induced silencing complex) for the degradation of the recombinant RNA and the corresponding host mRNA (Baulcombe 2002; Waterhouse et al. 2001). VIGS is advantageous over other methods due to its robustness, its ability to analyze genes that otherwise would produce lethal phenotypes when disrupted by conventional mutagenesis techniques, functional characterization of genes in different genetic backgrounds, and functional characterization of genes having redundant function within a gene family (Burch-Smith et al. 2004). Among the several viral vector systems used to trigger VIGS, Tobacco rattle virus (TRV; which contains bipartite positive-sense RNA genome RNA1 and RNA2 [Matthews 1991])-derived vectors are preferably used in dicots, because they produce mild symptoms on the host and have a broad host range (Dinesh-Kumar et al. 2003; Lu et al. 2003a; Ryu et al. 2004).

In this paper, we report the use of TRV-based VIGS to characterize previously identified plant factors that were suggested to be involved in Agrobacterium-mediated plant transformation and to identify novel plant genes that are involved in this process by using both the fast-forward (Baulcombe 1999; del Pozo et al. 2004; Lu et al. 2003b) and reverse genetic approaches (Ekengren et al. 2003; Liu et al. 2004a). This approach led to identification of additional plant factors involved in Agrobacterium-mediated transformation that previously remained unexplored due to the current limitation of other methods or to their incomplete use.

\section{RESULTS}

Susceptibility of Nicotiana benthamiana to A. tumefaciens.

$N$. benthamiana is a member of the Solanaceae, the nightshade family, and is susceptible to many plant viruses. It is widely used as a model plant to study gene silencing, plant-microbe interactions, and plant development (del Pozo et al. 2004;
Liu et al. 2002a and b, 2004a and b; Lu et al. 2003b; Ruiz et al. 1998). We have previously demonstrated the effect of gene silencing on shoots of $N$. benthamiana for many marker genes commonly used for VIGS in plants, including phytoene desaturase and magnesium phorphyrin chelatase genes (Ryu et al. 2004). Preliminary screenings were carried out to check the susceptibility of $N$. benthamiana to Agrobacterium infection by observing the growth of crown gall tumors upon infection with different tumorigenic strains of A. tumefaciens. Shoots of $N$. benthamiana were independently infected with different tumorigenic strains of A. tumefaciens (A348, A208, and A281 containing the octopine-type Ti plasmid pTiA6, the nopaline-type Ti plasmid pTiT37, and the agropine-type Ti plasmid pTiBo542, respectively, data not shown). A. tumefaciens A348 consistently produced larger crown galls than did the other strains and we therefore utilized this strain in our studies.

\section{VIGS identifies the involvement of expansin and nodulin-like proteins (NLP)} in Agrobacterium-mediated plant transformation.

To demonstrate that VIGS can be adapted as a useful tool for examining the biological function of plant genes that are predicted to be involved in Agrobacterium-mediated plant transformation, we silenced a set of plant genes that are either required or linked to involvement in Agrobacterium-mediated plant transformation. The plant genes selected for the reverse genetic studies are implicated in cell-wall attachment and metabolism, viz. arabinogalactan-like proteins $(A G L P), \alpha$-Expansin $(\alpha-E x p)$ (rat mutants [Zhu et al. 2003a]); cytoplasmic trafficking and nuclear import, viz. karyopherin $\alpha$-importin (Imp [Ballas and Citovsky 1997; Zhu et al. 2003a]); and VirE2-interacting protein (VIP1 [Tzfira et al. 2001]); T-DNA integration, viz. histone H2A (H2A [Mysore et al. 2000]); DNA repair, viz. $\operatorname{Rad} 23$ ( $R a d 23$ [Liu et al. 2003]); and others, viz. NLP (Ditt et al. 2001; Veena et al. 2003) and ethylene biosynthesis gene 1-aminocyclopropane-1-carboxylic acid $(A C C)$ synthase. Silencing of some of these genes in $N$. benthamiana produced abnormal developmental phenotypes including the severely stunted phenotype for $H 2 A$-silenced plants and the slightly dwarf phenotype for $N L P$-silenced plants. The silencing of the other tested genes did not produce developmental defects, and plants appeared similar to control plants infected with an "empty" vector (TRV::00).

We determined the efficacy of Agrobacterium infection on the shoots of $N$. benthamiana plants silenced for AGLP, $\alpha-E x p$, $N L P$, Imp, VIP1, H2A, Rad23, and ACC by performing in planta tumorigenesis assays with the oncogenic strain A. tumefaciens A348 as described above. Four weeks after infection, crown gall phenotypes were visually scored. Smaller tumors were observed in $N$. benthamiana shoots silenced for $\alpha$-Exp, $N L P$, Imp, and VIPI genes as compared with tumors on TRV::00-infected or wild-type plants (data not shown). Silencing of the AGLP, Rad23, and ACC genes in N. benthamiana had no effect on crown gall production, and the tumors were similar to those seen on control plants. We selected AGLP, with no altered tumor phenotype, as a negative control for the subsequent leaf-disk transformation assays.

\section{A fast-forward genetic approach identified several plant genes that affect Agrobacterium infection of $N$. benthamiana.}

To identify plant genes that are involved in Agrobacteriummediated plant transformation, a normalized $N$. benthamiana mixed-elicitor cDNA (cNbME) library was made in $p T R V 2$ vectors and was transformed into A. tumefaciens GV2260. DNA sequence analysis of 100 random NbcDNA clones indicated that the cDNA library had very low redundancy. Approximately 1,000 pTRV2 derivative clones (one gene per clone) from the 
cDNA library were individually inoculated, along with $p T R V 1$, into N. benthamiana plants in duplicates. Approximately 10 to $15 \%$ of the plants showed abnormal developmental phenotypes, including plants silenced for Actin and histone $H 3$ that were subsequently identified by sequencing the respective cDNA clones. The stems of all the silenced plants were inoculated with $A$. tumefaciens A348 and scored for tumorigenesis. After three rounds of screening, we identified 42 clones that, when used for VIGS, resulted in altered crown gall tumor phenotypes. We categorized these phenotypes as mild, super, and no tumors (Fig. 1A). The corresponding cDNA sequences from these clones were polymerase chain reaction (PCR)-amplified and sequenced. Among these sequences, we identified multiple members within a gene family (e.g., Rubisco). From this screening, 21 nonredundant plant genes were identified that could potentially be involved in Agrobacterium-mediated transformation. We termed these genes as $A C G$ (altered crown gall). The identified $A C G$ genes included genes that had been previously speculated (or shown) to be involved in Agrobacterium-mediated transformation (Skpl, Histone H2A, Histone H2b, Histone H3, and Actin), genes of known function but not previously suggested to be involved in Agrobacterium-mediated transformation (15 genes), and a gene that encodes a protein of unknown function. We further investigated the biological role of Histone H3 and Actin in Agrobacterium-mediated plant transformation. Detailed characterization of other genes is currently in progress and will be published elsewhere.

\section{A quantitative leaf-disk tumorigenesis assay corroborates the results of in planta tumor assays.}

We first tested the efficacy of gene silencing for the set of genes used in this study by quantitative real time reverse transcriptase-PCR (qRT-PCR) (Constantin et al. 2004). VIGS resulted in a decrease in the quantity of transcripts for all the genes studied. The percent decrease of the endogenous mRNAs varied with the genes that were silenced.

Having confirmed that VIGS resulted in lowered target RNA levels, we assayed the transformation efficiency in the silenced plants by performing leaf-disk transformation assays. We inoculated leaf disks from 3-week-old silenced plants, TRV::00 infected plants, and wild-type $N$. benthamiana plants with the oncogenic strain A. tumefaciens A348. This bacterial strain produced large green tumors on the leaf disks from wild-type plants within four weeks of infection (Fig. 1B). Leaf disks from the plants silenced for the $\alpha-E x p, N L P, \operatorname{Imp}, V I P 1, H 2 A$, Actin, and $H 3$ genes produced significantly fewer tumors than did those incited on TRV::00 and wild-type plants (Fig. 1B). $A G L P$-silenced $N$. benthamiana plants responded like wildtype and TRV::00-infected plants (Fig. 1B). These results were consistent with the in planta tumorigenesis assay. The weight (fresh and dry) of leaf disks (equal number) containing tumors was measured for the silenced and wild-type plants. The weight of leaf disks for the wild type, TRV::00 plants, and the $A G L P$-silenced plants was high (Fig. 1C), whereas the inoculated leaf disks from the plants silenced for $\mathrm{H} 2 \mathrm{~A}$ and Actin had at least a three- to fourfold lower weight than that observed in the control plants (Fig. 1C). Similarly, the biomass of the leaf disks (containing tumors) derived from plants silenced for $\alpha$ Exp, NLP, Imp, VIP1, and $H 3$ was significantly lower than that of in the control plants (Fig. 1C). The pattern of biomass differences in silenced plants was in accord with the data collected from the in planta tumorigenesis assays.

\section{Most silenced plants that were blocked} in stable transformation did not show altered cell division.

To rule out the possibility that the reduced tumorigenesis on the $\alpha$-Exp-, H2A-, Imp-, VIP1-, H3-, and NLP-silenced plants resulted from the downregulation of one or more genes involved in phytohormone response, we infected leaf disks of the silenced plants with the nontumorigenic strain A. tumefaciens GV2260 containing the binary vector $p C A S 1$ (Nam et al. 1999). pCAS1 contains a nos-bar gene as a selectable marker. We counted the number of leaf disks that produced one or more glufosinate ammonium (GF)-resistant calli on callusinducing medium (CIM) containing GF. The results of these experiments depicted in Figure $2 \mathrm{~A}$ and $\mathrm{B}$, indicated that silencing of $\alpha$-Exp, $H 2 A, \operatorname{Imp}, V I P 1, H 3$, and $N L P$ in $N$. benthamiana resulted in recalcitrance to stable transformation. Silencing of $V I P 1, H 3$, and $H 2 A$ had a large effect on stable transformation, resulting in a lower percentage of disks with GF-resistant calli $(8.5,2.6$, and $1.2 \%)$, as compared with the controls (87.6 and 91.1\%; Fig. 2B). Although the silencing of $\alpha$-Exp, Imp, and $N L P$ genes in $N$. benthamiana gave higher percentages of GF-resistant calli $(53,32.5$, and 30\%, respectively), they were significantly lower than those observed in the TRV::00-infected plants (Fig. 2B).

To determine the effect of gene silencing on cell division, uninoculated leaf disks of the silenced plants ( 3 weeks postsilencing) were cultured on a nonselective CIM for 4 weeks. Most of the silenced plants had no observable differences in cell division and cell proliferation (Fig. 2C). However, silencing of the Actin gene in $N$. benthamiana resulted in reduced cell proliferation (Fig. 2C). Callus formation was almost completely inhibited in Actin-silenced leaves. A slight delay in callusing, which did not significantly affect callus formation, was also observed in the plants silenced for the $\mathrm{H} 2 \mathrm{~A}$ gene (Fig. 2C). Because silencing of the Actin gene resulted in defective cell proliferation, this gene was not investigated further.

\section{A transient transformation assay reveals that Histone $\mathrm{H3}$ and NLP are most likely involved in later steps of Agrobacterium-mediated transformation, whereas $\alpha$-Expansin is involved \\ during the early steps of transformation.}

We used a sensitive fluorometric assay that quantifies GUS ( $\beta$-glucuronidase) activity (Nam et al. 1999), to determine the steps that were disrupted in $\alpha-E x p-, H 3-$, and $N L P$-silenced plants. Because the functional role of Imp and VIPI in nuclear import of the T-DNA has been described (Ballas and Citovsky 1997; Tzfira et al. 2001), we did not perform the transient assays on these gene-silenced plants. The step at which Histone $H 2 A$ is involved in T-DNA transformation is known (Mysore et al. 2000), and therefore, we used $H 2 A$-silenced plants as a positive check in the transient transformation assays. For transient transformation assays, we used the nontumorigenic strain A. tumefaciens GV2260, containing the binary vector $p B I S N 1$ harboring the uidA-intron gene in its T-DNA as a reporter (Narasimhulu et al. 1996). We detected transient GUS expression in TRV::00 control plants and $\alpha$-Exp-, $H 3$-, $N L P$-, and $H 2 A$-silenced plants within two days of cocultivation with $A$. tumefaciens (Fig. 3). The early detection of GUS expression most likely represents transient expression of the uidA gene, which is suggestive that the plants are not blocked at the early stages of transformation. Fluorometric assays were used to quantify reporter gene expression in two duplicate experiments by harvesting leaf disks at regular intervals. Figure 3 details the pattern of GUS activity determined in the silenced plants as compared with TRV::00 control plants. Our observation suggests that silencing of $H 3, N L P$, and $H 2 A$ genes in $N$. benthamiana most likely blocks the later steps of transformation. The data collected from the $\mathrm{H} 2 \mathrm{~A}$-silenced plants are consistent with its known biological roles in T-DNA integration (Mysore et al. 
2000). The reduced GUS activity in $\alpha$-Exp-silenced plants at early stages of transformation ( 2 days postinfection [dpi]) suggests that $\alpha$-Expansin may be involved during the early stages of transformation (Fig. 3).

A

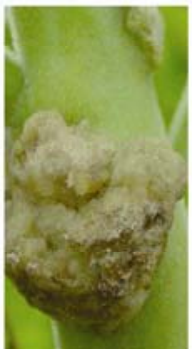

Wild-type tumor

B

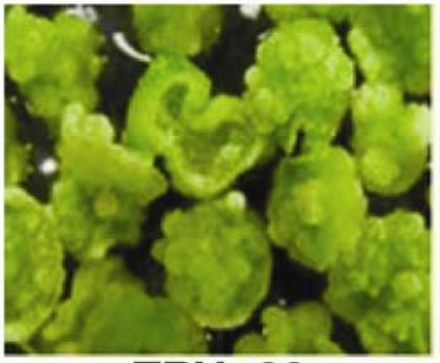

TRV::00

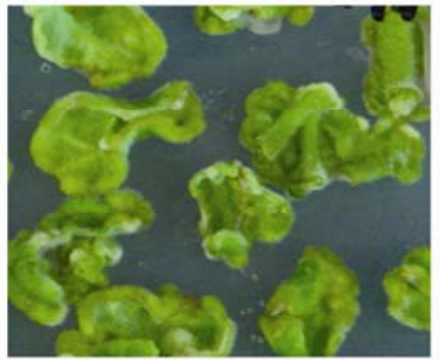

TRV::LeImp

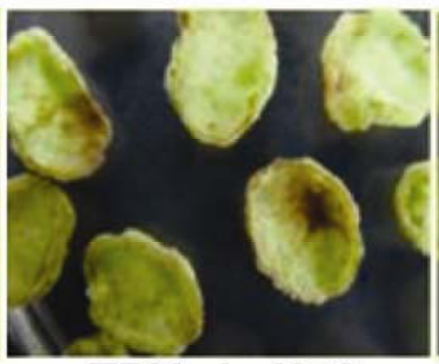

TRV::LeH2A

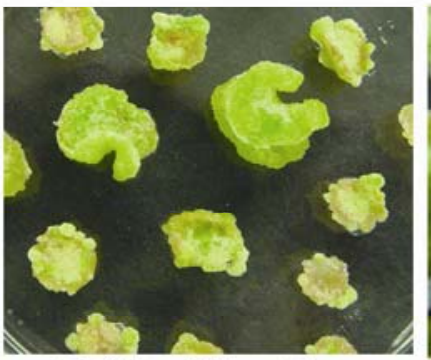

TRV::Nb $\alpha-E x p$

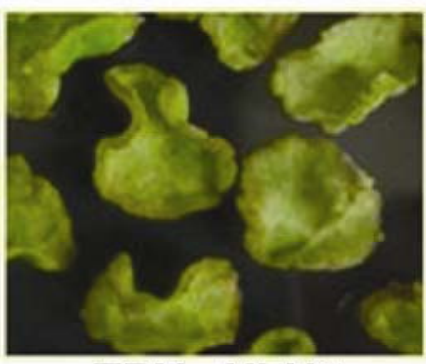

TRV:: $\mathbf{N b H 3}$

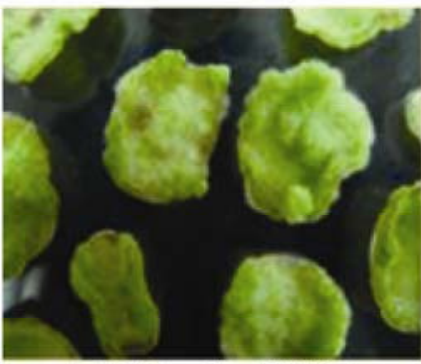

TRV::LeVIP1

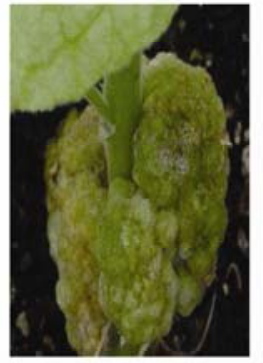

Super tumor
Expansins are encoded by a superfamily of genes with mainly four different classes, $\alpha$-Exp, $\beta$-Exp, Expansin-like $\alpha$
C

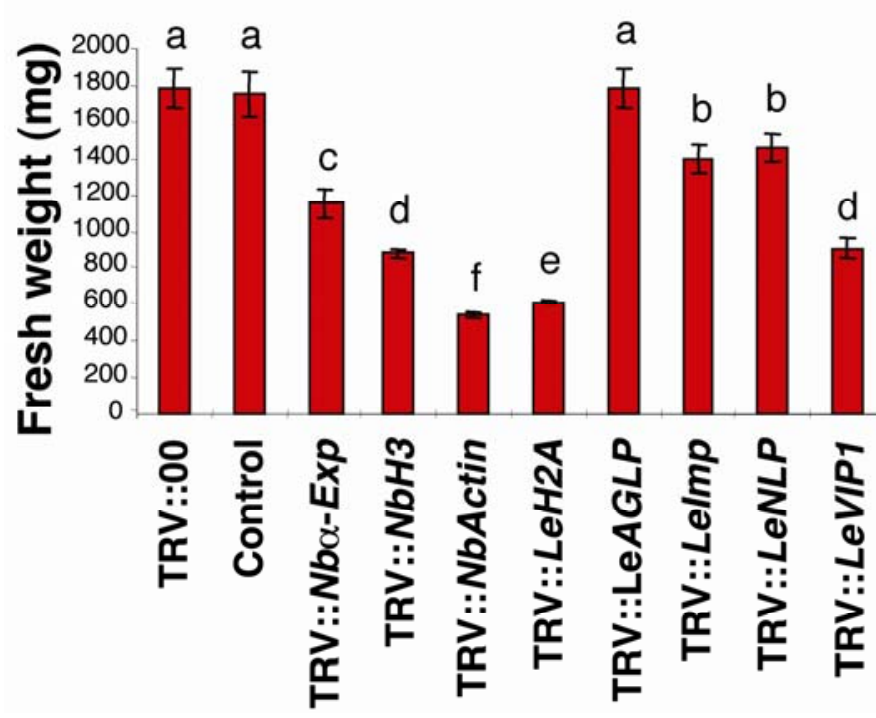

D

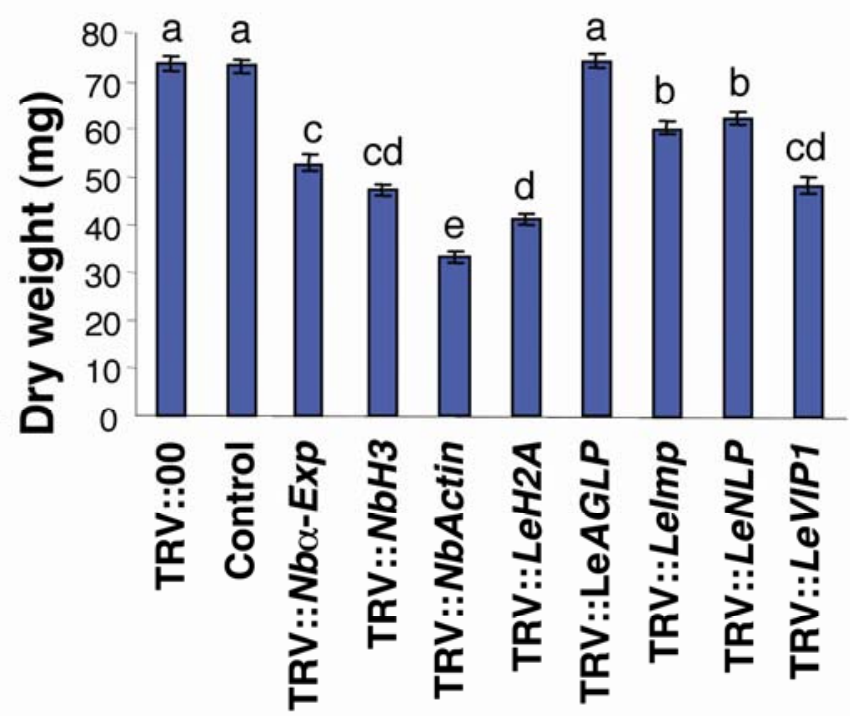


$(\operatorname{Exp}-A)$, and Expansin-like $\beta \quad(\operatorname{Exp}-B)$ (Sampedro and Cosgrove 2005). Each class is further divided into subclasses comprised of closely related gene-family members. For example, the $\alpha$-Exp family is divided into 12 clades (Sampedro and Cosgrove 2005). We speculated that the Exp gene is involved in Agrobacterium attachment, and therefore, we designed experiments to investigate whether the $\alpha$-Exp silenced plants had a defect in attaching $A$. tumefaciens. We recently developed a system to label bacteria with GFPuv by constructing a broad host range plasmid ( $p D S K-G F P u v)$ that can express GFPuv (K. Wang and K. S. Mysore; unpublished results). Bacterial strains containing $p D S K-G F P u v$ emit strong green fluorescence under long wavelength ultraviolet light. We transferred $p D S K-G F P u v$ to both the transfer-efficient nontumorigenic strain A. tumefaciens GV2260 and the attachment-deficient mutant $\operatorname{chvB^{-}}$ (A192) (Douglas et al. 1985) and performed attachment assays on cut-leaf segments of $\alpha$-Exp-silenced and TRV::00-infected control plants as described below. Agrobacterium attachment was not significantly affected in $\alpha$-Expsilenced plants at either high $\left(5 \times 10^{8} \mathrm{CFU} / \mathrm{ml}\right)$ or low $\left(1 \times 10^{8}\right.$ $\mathrm{CFU} / \mathrm{ml}$ ) bacterial concentrations (Fig. 4A) as compared with control (TRV::00) plants. Binding of the attachment mutant $\operatorname{chv} B^{-}$was barely detected in the above assays, whereas the fluorescent spots were more intense in the attachment-proficient strain A. tumefaciens GV2260 (Fig. 4A). Our results suggest that $\alpha$-Exp used in this study is most likely not required for Agrobacterium attachment to the plant cell surface and therefore the reduction in transient transformation for $\alpha$-Expsilenced plants cannot be attributed to a reduction in the efficiency to attach A. tumefaciens.

To characterize further the role of $\alpha-\operatorname{Exp}$ in transformation, we investigated if $N b \alpha$-Exp is differentially expressed during Agrobacterium infection. Wild-type $N$. benthamiana plants were vacuum-infiltrated with either buffer or the nontumorigenic A. tumefaciens At804 (a T-DNA transfer competent nononcogenic strain containing the disarmed Ti plasmid plus binary vector $p B I S N 1$ ) or A136 (nononcogenic strain that lacks a Ti plasmid). Leaf samples were collected at different times after infection, and the accumulation of $\alpha$-Exp mRNA was quantified by semiquantitative RT-PCR and qRT-PCR. The $N b \alpha$-Exp gene was induced upon vacuum infiltration as early as $3 \mathrm{~h}$ postinfiltration (hpi) in both buffer and A. tumefaciens-infected leaves. Our data indicate that $\alpha$-Exp is slightly induced upon infiltration stress. Interestingly, $\mathrm{Nb} \alpha$ Exp was induced to a greater extent (twofold) at $6 \mathrm{hpi}$ in response to the T-DNA transfer-competent strain (At804), as compared with the buffer or the nontumorigenic strain A136 (Fig. 4B). Induction of the $N b \alpha$-Exp gene in plants infiltrated with the transfer-competent strain of $A$. tumefaciens was not significant after 6 hpi (Fig. 4B). These data are in accord with the hypothesis that infection by transfer-competent $A$. tumefaciens strains modulates host gene expression at early times so as to facilitate genetic transformation (Veena et al. 2003).

\section{Histone $\mathrm{H3}$ gene-silenced plants are partially blocked in T-DNA integration.}

The role of Histone H2A in Agrobacterium T-DNA integration is well characterized (Mysore et al. 2000; Yi et al. 2002, 2006). In this study, we observed that histone $H 3$-silenced plants were deficient in stable transformation but not in transient transformation, suggesting a block in T-DNA integration (Figs. 1, 2, and 3). To confirm further that T-DNA integration was blocked in $H 3$-silenced plants, we inoculated leaf disks derived from TRV::00-inoculated and $H 3$-silenced $N$. benthamiana plants with the disarmed strain A. tumefaciens GV2260, containing the binary vector $p K M 1$ (Mysore et al. 1998) carrying a promoterless uidA-intron gene within the T-DNA. In this case, the expression of the uidA gene in plants is dependent upon T-DNA integration downstream of a plant promoter. Significantly less GUS activity was detected in leaf disks of $\mathrm{H3}$ silenced plants at 15 and $24 \mathrm{dpi}$ as compared with leaf disks derived from TRV::00 plants (Fig. 5A). The above observation reinforces the role of histone $\mathrm{H} 3$ in T-DNA integration.

To provide further evidence that the $H 3$-silenced plants are deficient in T-DNA integration, we inoculated leaf disks derived from TRV::00 and $H 3$-silenced $N$. benthamiana plants with the disarmed strain A. tumefaciens GV2260, containing the binary vector $p B I S N 1$, and performed semiquantitative PCR and qPCR to quantify the amount of integrated uidA gene in leaf calli at $24 \mathrm{dpi}$ as described earlier ( $\mathrm{Li}$ et al. 2005). The amount of PCR products specific to uidA gene, determined by qPCR, was significantly lower (approximately 66\%) in $\mathrm{H3}$ silenced plants as compared with TRV::00 plants (Fig. 5B). No Agrobacterium contamination was detected in the plant DNA samples used for PCR analyses (Fig. 5C).

\section{DISCUSSION}

The molecular mechanism by which A. tumefaciens genetically transform plants has been an area of extensive research over the last few decades (Anand and Mysore 2005; Christie 2004; Gelvin 2003a; Tzfira and Citovsky 2002; Zhu et al. 2000). Recent research efforts have been directed towards better understanding the biological role played by the host partners in infection. In this paper, we describe a novel method, based on VIGS, for identification and functional characterization of host-cell factors involved in Agrobacterium-mediated plant transformation. Using a reverse genetic approach, we validated the VIGS technology to study Agrobacterium-plant interactions. To identify novel plant genes that play a vital role during Agrobacterium-mediated transformation, we utilized a VIGS-mediated fast-forward genetics approach (Baulcombe 1999). We have, to date, silenced approximately 1,000 normalized random cDNA clones and have performed in planta tumor assays on these plants. From this screen, we have identified 21 $A C G$ genes that may be involved in Agrobacterium-mediated transformation. The percentage of silenced plants that have an ACG phenotype is higher (approximately 2\%) than reported

Fig. 1. In planta and leaf-disk tumorigenesis assays in Nicotiana benthamiana. A, In planta tumorigenesis assay. Fast-forward genetics approach to identify genes whose silencing resulted in altered crown gall (ACG) phenotypes. A normalized N. benthamiana cDNA library cloned into TRV2 vector by GATEWAY cloning and approximately 1,000 TRV2-derivative cDNA clones were randomly used for silencing in N. benthamiana. An in planta tumorigenesis assay was performed on stems of the silenced plants ( 3 weeks postsilencing) by inoculating with the tumorigenic strain of Agrobacterium tumefaciens A348, and the crown gall phenotypes on stems were recorded visually and were classified into normal, no tumor, mild tumor, and super tumor categories. B, Leaf-disk tumorigenesis assay on the silenced plants. Leaves from the silenced plants were surface-sterilized, and leaf disks from these leaves were inoculated with A. tumefaciens A348 and were incubated on hormone-free Murashige-Skoog medium. Photographs were taken four weeks after infection. C, and $\mathbf{D}$, Quantification of the relative biomass of leaf disks with tumors. The leaf disks derived from the silenced plants were inoculated with $A$. tumefaciens A348 and the fresh (panel C) and dry (panel D) weights of the leaf disks were measured four weeks after inoculation to quantify the relative mass of the leaf disks with tumors. The experiments were replicated twice with a minimum of 150 leaf disks for each silenced plant. Letters indicate significant difference using Fisher's least significant difference test at $P=0.05$. 
A

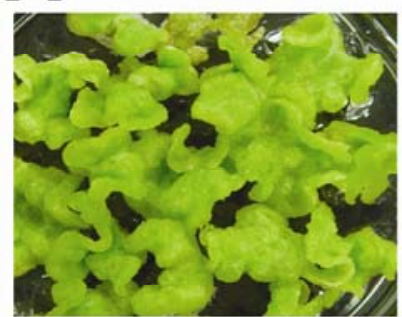

TRV::00

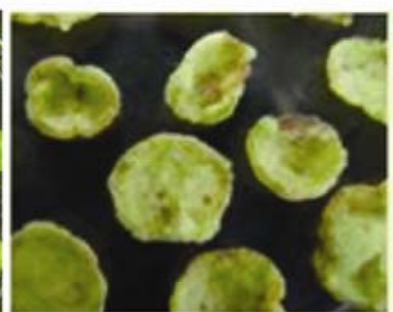

TRV::LeH2A

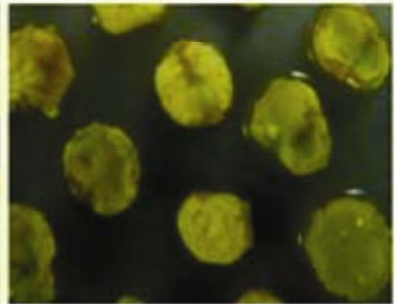

TRV::NbH3

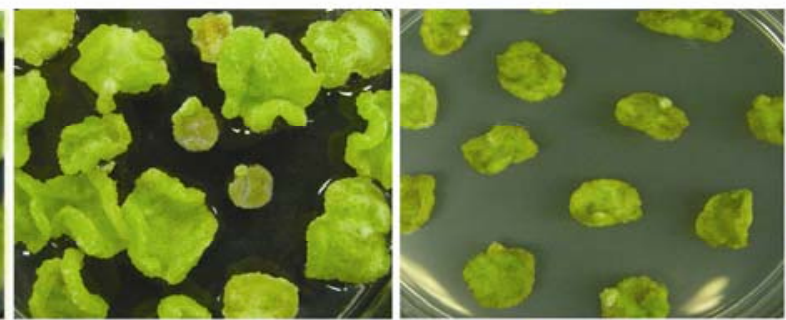

TRV::LeVIP1

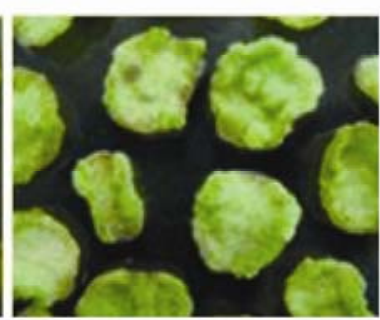

TRV::LeNLP

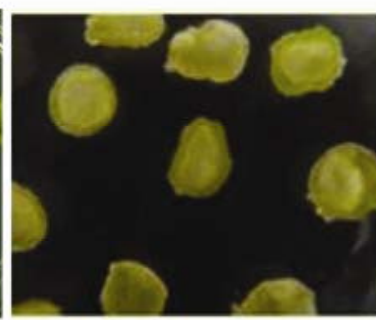

TRV::NbActin

B

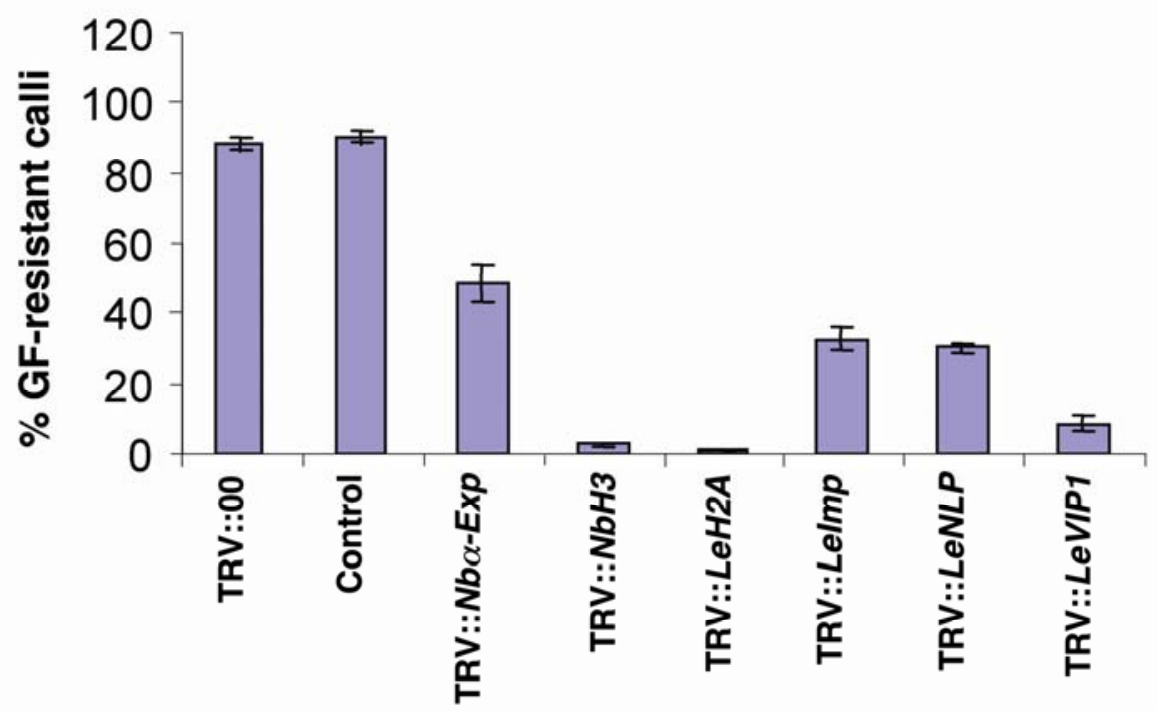

C

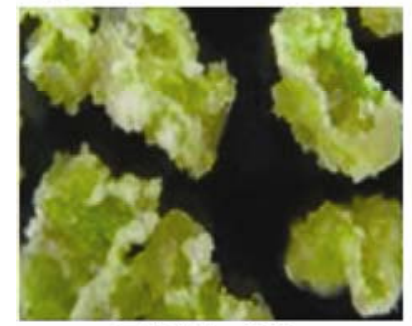

TRV::00

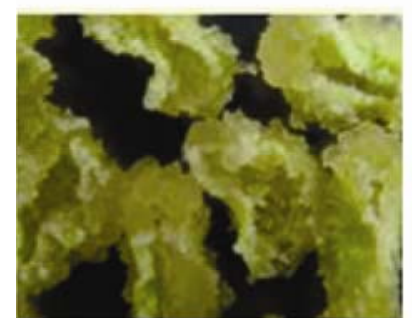

TRV::Lelmp

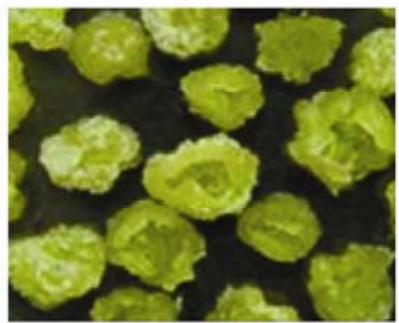

TRV::LeH2A

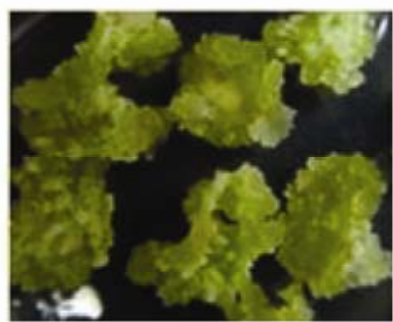

TRV::Nb $\alpha-E x p$

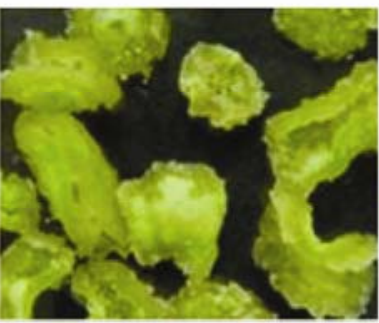

TRV::NbH3

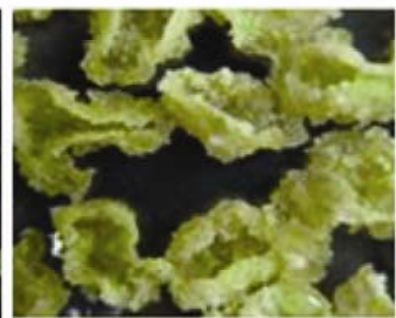

TRV::LeVIP1

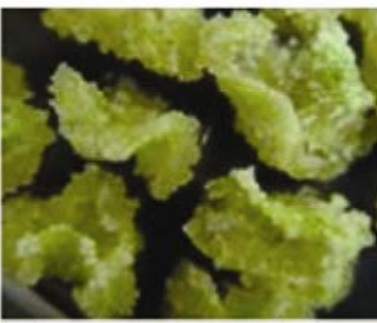

TRV::LeNLP

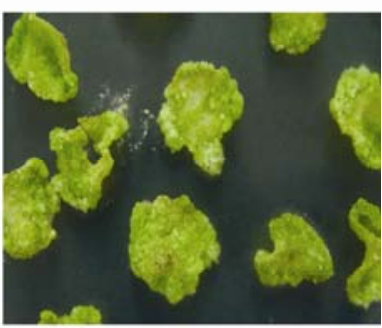

TRV::NbActin 
earlier in the Arabidopsis rat mutant screening (Nam et al. 1999). It is possible that there are few false positives in the list of $21 A C G$ genes. We are currently performing other quantitative transformation assays to remove false positives.

To demonstrate the robustness of this tool in gene discovery, we used a reverse genetics approach to silence the plant genes $\alpha-\operatorname{Exp}, N L P, A G L P, \operatorname{Rad} 23$, and $A C C$ that we speculate are involved in Agrobacterium-plant interaction, based on previously published data (Ditt et al. 2001; Gaspar et al. 2004; Veena et al. 2003; Zhu et al. 2003a). Expansin belongs to a large family of proteins that mediate cell-wall loosening by disrupting hydrogen bonds between cellulose microfibrils and matrix polysaccharides, thereby enabling stress-related relaxation of isolated cells (Cosgrove 2000). The role of Expansin is postulated mainly to be in growth and cell-wall modifications (Cosgrove et al. 2002; Lee et al. 2001), whereas little is known regarding its role in plant defenses. There is evidence suggesting that both plant cell-wall architecture and remodeling play critical roles in Agrobacterium attachment and biofilm formation (Gaspar et al. 2004; Matthysse 1987; Wagner and Matthysse 1992; Zhu et al. 2003b). The strong rat phenotype of the ratT18 (Zhu et al. 2003a), a $\beta$-Expansin mutant, lead us to hypothesize that Expansin proteins probably modulate Agrobacterium attachment to plant cells or import of T-complex by cell-wall relaxation and extension upon infection. However, complementation of ratT18 mutant has not been reported. Using stable transformation assays, we show that $\mathrm{Nb} \alpha$ Exp-silenced plants are recalcitrant to genetic transformation by $A$. tumefaciens (Figs. $1 \mathrm{C}$ and $\mathrm{D}$ and $2 \mathrm{~B}$ ). The data from the GUS assay suggest that $N b \alpha-\operatorname{Exp}$ may be involved during early stages of T-DNA transfer (Fig. 3). However, no deficiency in Agrobacterium attachment was observed in the $\mathrm{Nb} \alpha$ Exp-silenced plants (Fig. 4A). The twofold higher expression of $N b \alpha-E x p$ at early stages by an A. tumefaciens transfer-competent strain, as compared with the nontumorigenic strain $A$. tumefaciens A136 (Fig. 4B), further reinforces our suggestion that this gene is involved in the early stages of T-DNA transfer to the plant cell.

Genes similar to the early nodulin ENOD18 of Vicia faba (Veena et al. 2003) and NLP (Ditt et al. 2001) have previously been shown to be differentially expressed during Agrobacterium infection. The Rhizobium nod genes specify the synthesis of nodulation (Nod) factors, which are lipo-chitooligosaccharides (Denarie et al. 1996). These Nod factors elicit activation of plant genes in legumes that are specifically induced during early stages of nodulation (early nodulin genes), cortical cell division, and programming plant organogenesis that leads to nodule formation (Cohn et al. 1998; Schultze and Kondorosi 1998). In this report, we provide experimental evidence implicating NLP in Agrobacterium-mediated plant transformation (Figs. 1 and 2). Based on our transient transformation assays (Fig. 3), we speculate that downregulation of a gene encoding NLP affects later steps of Agrobacterium infection.

DNA repair has been shown to play a critical role in the TDNA integration event (Nam et al. 1997; van Attikum et al. 2001). Silencing of Rad23 in N. benthamiana did not affect the plant's ability to be transformed by A. tumefaciens in planta (data not shown). Veena and associates (2003) recently showed that many plant defense-related genes are suppressed during Agrobacterium-mediated transformation. Ethylene production is one of the major defense responses in plants, and therefore, we checked the effect of silencing an ethylene synthesizing gene (ACC synthase) on Agrobacterium-mediated transformation. Using VIGS, we could not show the involvement of ethylene in Agrobacterium-mediated transformation. Similarly, we could not verify the involvement of AGLP in Agrobacterium-mediated plant transformation, probably due to the low amino-acid sequence similarity between the LeAGLP sequence and the previously described arabinogalactan protein (RAT1; Gaspar et al. 2004). Secondly, arabinogalactan proteins are represented by a large gene family in Arabidopsis. Due to the unavailability of gene sequences for all the arabinogalactan genes in tomato or $N$. benthamiana, we are currently unable to address this issue. VIGS technology, as with any other functional genomic tool, has certain limitations. Complete elimination of target gene transcripts is not possible. The use of heterologous gene sequences for silencing may not always be successful due to low nucleotide sequence homology between genes from two plant species as ascertained from the above discussed examples.

From the fast-forward genetic screening, we identified 21 $A C G$ genes that are likely to be involved in Agrobacteriummediated transformation. Further studies (quantitative assays) are currently underway to confirm the involvement of these

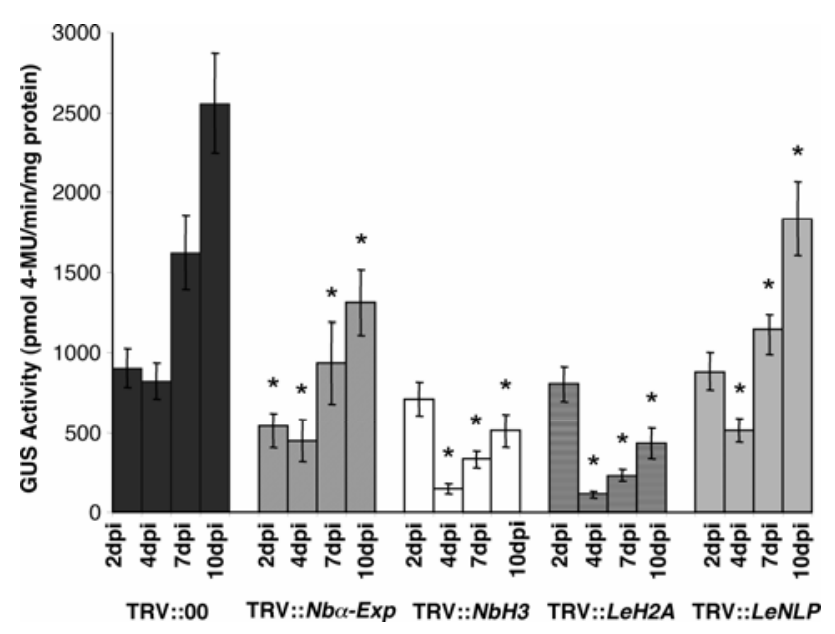

Fig. 3. Quantification of transient transformation in gene-silenced plants. Leaf disks of silenced plants were inoculated with a nontumorigenic strain, Agrobacterium tumefaciens GV2260, harboring the binary vector pBISN1. The inoculated leaves were collected at 2, 4, 7, and 10 days postinoculation (dpi), and GUS activity was measured by recording the fluorescence of 4-methylumbelliferone (4-MU) (Jefferson et al. 1987). Silencing of $\alpha$-Expansin $(\alpha$-Exp) resulted in deficiency in an early transient transformation step, while silencing of $N L P, H 2 A$, and $H 3$ had no affect on transient GUS expression but significantly decreased stable GUS activity (4, 7, and 10 days). Asterisks denote values that are significantly different between treatments by ANOVA at $P=0.05$.

Fig. 2. Leaf-disk assays for characterizing stable transformation and effect of gene-silencing on cell division. A, Leaf-disk transformation assay. Leaf disks of silenced and TRV::00-infected plants were inoculated with a nontumorigenic strain, Agrobacterium tumefaciens GV2260, harboring the binary vector pCAS1 and were incubated on callus inducing medium (CIM) with glufosinate ammonium (GF). Photographs were taken four weeks after inoculation. B, Quantification of GF-resistant calli. Percentage of leaf disks derived from silenced plants that produced GF-resistant calli were compared with the percentage of leaf disks derived from control and TRV::00-infected plants that produced GF-resistant calli. C, Callus production by leaf disks of silenced and nonsilenced plants. The effect of gene silencing on cell division was evaluated by placing leaf disks derived from TRV::00-infected and silenced plants on nonselective CIM for four weeks and by recording differences in callus production. Silencing of Actin gene severely affected cell division, whereas silencing of other genes did not significantly affect cell division. 
genes in transformation. It is possible that silencing of some of these genes may affect phytohormone synthesis or phytohormone response or affect cell division, causing alteration in the crown gall phenotype. We chose to characterize further the requirement of Actin and Histone $\mathrm{H} 3$ genes in Agrobacteriummediated plant transformation. Both Actin and Histone $\mathrm{H3}$ were speculated to be required for Agrobacterium-mediated plant transformation (Zhu et al. 2003a). The plant actin cytoskeleton provides a dynamic cellular component that is in-
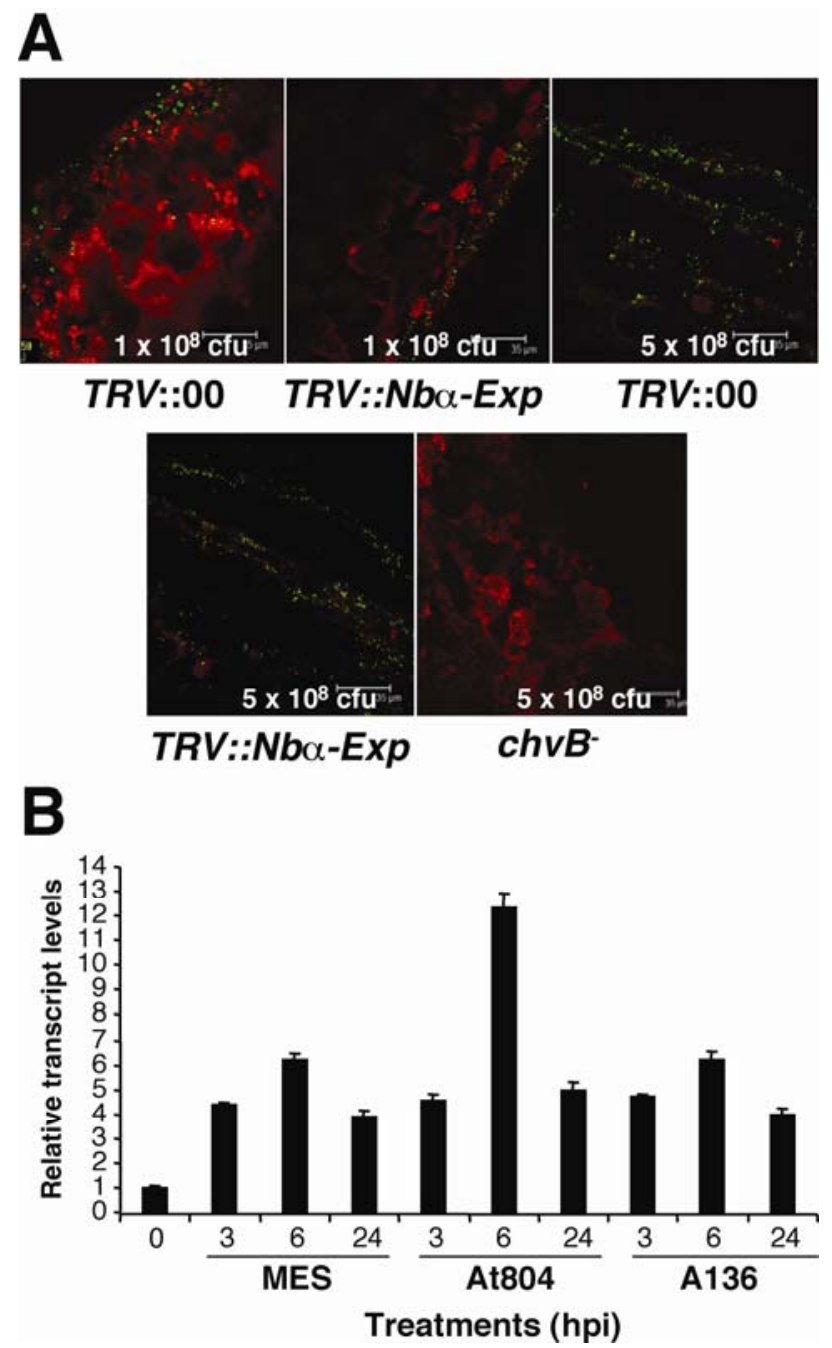

Fig. 4. Role of $\alpha$-Expansin $(\alpha$-Exp) in Agrobacterium-mediated plant transformation. A, Agrobacterium attachment assay. Axenic cut-leaf segments derived from $\alpha$-Exp-silenced and TRV::00-inoculated plants were cocultivated with a disarmed strain, A. tumefaciens GV2260, carrying the binary vector $p D S K-G F P u v$ at final concentrations of $1 \times 10^{8}$ and $5 \times 10^{8}$ $\mathrm{CFU} / \mathrm{ml}$ or the $\operatorname{chv} B^{-}$attachment-deficient strain $\left(5 \times 10^{8} \mathrm{CFU} / \mathrm{ml}\right)$. After cocultivation $(12 \mathrm{~h})$, leaf segments were washed to remove unattached bacteria, and the fluorescent bacteria attached to leaf tissues were visualized along the cut surfaces, using a Leica TCS SP2 AOBS confocal system, using excitation at $488 \mathrm{~nm}$ and emitted light from 500 to $600 \mathrm{~nm}$ with a $20 \times$ dry objective. Experiments were repeated three times. B, Quantitative real time reverse transcriptase-polymerase chain reaction (qRT-PCR) analysis of $\alpha$-Exp transcripts in Nicotiana benthamiana upon inoculation with $A$. tumefaciens. Wild-type $N$. benthamiana plants were individually inoculated with GV2260, a transfer-efficient Agrobacterium strain, harboring the binary vector $p B I S N 1$ (At804) or an avirulent Agrobacterium strain that lacks the Ti plasmid (A136), at a final concentration of $1 \times 10^{7}$ $\mathrm{CFU} / \mathrm{ml}$, or MES buffer (control) by vacuum infiltration. The inoculated leaf samples were periodically collected at 3,6 , and $24 \mathrm{~h}$ postinoculation (hpi), and were subject to qRT-PCR. Leaf samples from an uninoculated (0 h) plant were used as a control to determine the basal expression level of Nb $\alpha$-Exp. All the experiments were done with at least three replications. volved in the maintenance of cell shape and structure. Actin cytoskeletal elements are located near the plasma membrane and are, therefore, uniquely positioned to receive and transduce information. The actin cytoskeleton also plays critical roles in the establishment and maintenance of cell polarity, providing tracks for the movement of assorted cellular organelles and responses to numerous environmental stimuli (Staiger 2000; Wasteneys and Galway 2003). Many cytoskeleton genes, including Actin, have been implicated in cytoplasmic trafficking of the T-complex (e.g., rat mutants; Zhu et al. 2003a; S. B. Gelvin, personal communication) but are yet to

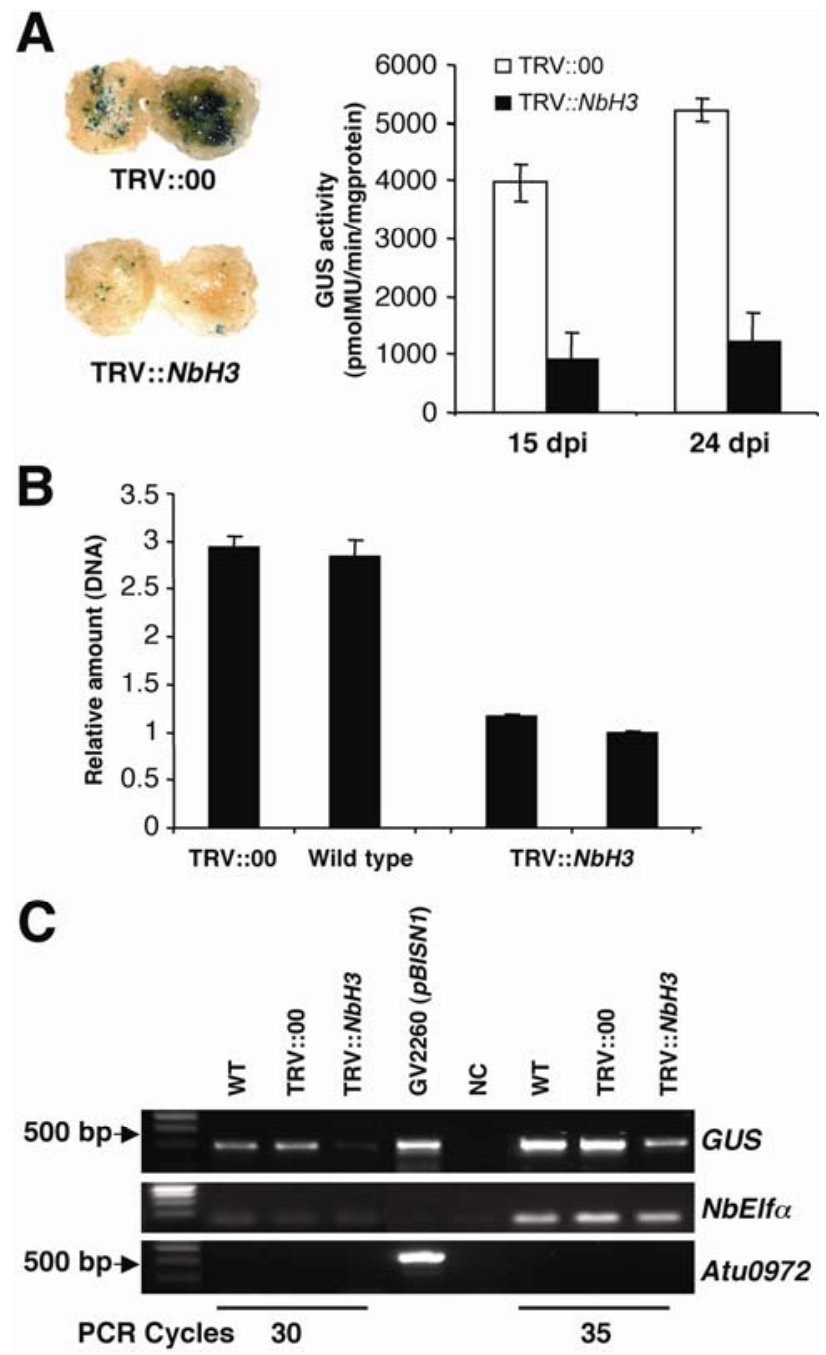

Fig. 5. Transfer DNA (T-DNA) integration assay for $H 3$-silenced plants. A, Promoter trap assay. The leaf disks of the $H 3$-silenced and empty vector (TRV::00)-inoculated Nicotiana benthamiana plants were infected with nontumorigenic strain Agrobacterium tumefaciens GV2260 harboring the promoter trap binary vector $p K M 1$ harboring a promoterless $G U S$ gene within the T-DNA (Mysore et al. 1998). The inoculated leaf disks were incubated in callus-inducing medium (CIM) without any selection and were collected at 15 and 24 days postinoculation (dpi) and were either stained with X-gluc (left panel) or were used to measure GUS activity (right panel). The GUS activity derives from an integrated T-DNA. B, and $\mathbf{C}$, Quantitative poloymerase chain reaction (qPCR) and semiquantitative PCR analyses to determine the amount of integrated T-DNA. The leaf disks of the H3-silenced and empty vector (TRV::00)-inoculated $N$. benthamiana plants were infected with nontumorigenic strain A. tumefaciens GV2260 harboring the binary vector $p B I S N 1$. The inoculated leaf disks were incubated in CIM without selection and were collected at $21 \mathrm{dpi}$. DNA was isolated from the calli and was PCR-amplified with primers specific to GUS or elongation factor $\alpha(N b E l f \alpha)$ or an A. tumefaciens gene (Atu0972). WT $=$ wild-type $\mathrm{NC}=$ no template control. 
be verified in terms of their biological role in Agrobacteriummediated plant transformation. The silencing of an actin gene from $N$. benthamiana resulted in a dwarf phenotype and produced very few tumors upon inoculation with tumorigenic $A$. tumefaciens (Fig. 1B, C, and D). Silencing of Actin severely affected plant cell division, even in the absence of transformation (Fig. 2C). This could probably have resulted in completely eliminating the plant's ability to be transformed by the leafdisk transformation assay (Fig. 2A and B). Despite the possibility that Actin may be involved in cytoplasmic trafficking of the T-complex, we were unable to show this using a genesilencing approach. It is not known if the Arabidopsis rat mutants (Zhu et al. 2003a) that have mutations in Actin genes are affected in cell division.

The role of histones in T-DNA integration is speculated based on reports that mutation of a class of 'replacement' histones resulted in a strong rat phenotype and that overexpression of histones increased transformation (Mysore et al. 2000; Yi et al. 2002, 2006; Zhu et al. 2003a). Increased levels of transcripts for core histone genes occur during the later stages of transformation by transformation-proficient strains of $A$. $t u$ mefaciens but not by a transformation-deficient strain, suggesting their roles in Agrobacterium-mediated transformation (Veena et al. 2003). It is interesting to note that a T-DNA insertion between two closely spaced replacement Histone $\mathrm{H3}$ genes resulted in a rat phenotype (Zhu et al. 2003a). One of the rat mutants for Histone H3 (ratT17) was recently complemented and therefore appears to be required for efficient Agrobacterium-mediated plant transformation (Zhu et al. 2003a). However, further characterization of this rat mutant is necessary. In our study, silencing of a Histone $\mathrm{H3}$ gene in N. benthamiana resulted in an abnormal developmental phenotype. Silencing of $H 3$ affected T-DNA integration without affecting transient transformation (Figs. 3 and 5A). T-DNA integration events were significantly reduced in the $H 3$-silenced plants as compared with TRV::00-inoculated plants (Fig. 5B and C). These results are consistent with our speculation that histones are involved in T-DNA integration.

Silencing of 'housekeeping' genes such as Histones (H3, $H 2 A$ ), Actin, and $\alpha$-tubulin resulted in developmentally abnormal phenotypes. Silencing of these genes may disrupt general cell functions and may cause pleiotropic effects on cellular processes. Therefore, it is possible that the housekeeping genes themselves are not involved directly in the transformation process but rather affect other downstream genes, which in turn are directly involved in the transformation. However, the observations that Arabidopsis rat mutants ( $\mathrm{H} 2 \mathrm{~A}$ and $\mathrm{H3}$; Mysore et al. 2000; Zhu et al. 2003a) do not have any abnormal developmental phenotypes suggest that histones may be directly involved in Agrobacterium-mediated plant transformation. Our current focus is towards characterizing the roles of the plant genes that are described in this article and continuing the search for additional plant genes that are involved in Agrobacterium-mediated plant transformation. Because the list of genes we identified does not overlap completely with that of previously identified $R A T$ genes, we conclude that our approach is complementary to other previously published approaches.

\section{MATERIALS AND METHODS}

\section{Plant material and bacterial culture preparation.}

Seeds of $N$. benthamiana were germinated in flats using a soilless potting mixture, BM7 (Berger Co., Quebec, Canada). Two-week-old seedlings were transplanted to $10-\mathrm{cm}$ diameter round pots containing BM7, with one plant per pot. The plants were regularly fertilized (20-10-20) and given a soluble trace element mix (The Scotts Co., Marysville, OH, U.S.A.) and were maintained under greenhouse conditions $\left(23 \pm 3^{\circ} \mathrm{C}, 70 \%\right.$ humidity, 16-h photoperiod with supplemental lighting 50 to $100 \mu \mathrm{E} \mathrm{s}^{-1} \mathrm{~m}^{-2}$ ). One- to three-week-old plants were used for silencing experiments.

All Agrobacterium strains were cultured in Luria-Bertani (LB) medium supplemented with the appropriate antibiotics (rifampicin, $10 \mu \mathrm{g} / \mathrm{ml}$; kanamycin, $50 \mu \mathrm{g} / \mathrm{ml}$ ) at $28^{\circ} \mathrm{C}$. Overnight bacterial cultures were washed with distilled water; induced on agro-induction medium $\left({ }^{1} / 10\right.$ Murashige-Skoog [MS] basal salt; $0.5 \mathrm{mg} 2-\mathrm{N}$-morpholino-ethanesulfonic acid [MES] per milliliter, $\mathrm{pH} 5.8$, and $1 \%$ glucose) supplemented with acetosyringone $(150 \mu \mathrm{g} / \mathrm{ml})$ at room temperature $\left(24^{\circ} \mathrm{C}\right)$ for 14 to $16 \mathrm{~h}$. The induced cultures were washed with sterile distilled water and resuspended in $0.9 \% \mathrm{NaCl}$ at $10^{9} \mathrm{CFU} / \mathrm{ml}$ for in vivo shoot and leaf-disk tumorigenesis assays. A concentration of $10^{9} \mathrm{CFU} / \mathrm{ml}$ was also used for the transient transformation assays.

\section{Plasmid construction.}

pTRV1 and $p T R V 2$ VIGS vectors (Liu et al. 2002b) were obtained from S. P. Dinesh-Kumar, Yale University (New Haven, CT, U.S.A.). For reverse genetic experiments, the tomato heterologs for the following set of genes were identified from the TIGR database. Tomato open reading frames corresponding to LeAGLP, LeNLP, LeImp, LeVIP1, LeH2A, LeRad23, and LeACC were amplified by RT-PCR with adapter (attB1 5'GGGGACAAGTTTGTACAAAAAAGCAGGCT-3' and attB2 5'-GGGGACCACTTTGTACAAGAAAGCTGGGT-3'). The $N b \alpha$-Exp was RT-PCR-amplified from a $N$. benthamiana cDNA using the adapter GATEWAY primers. The PCR products were cloned into the VIGS vector $p T R V 2$ (Liu et al. 2002a and b) by GATEWAY cloning according to the manufacturers instructions (Invitrogen Life Technologies, Carlsbad, CA, U.S.A.). The constructs were confirmed by DNA sequencing and were introduced into A. tumefaciens GV2260 by electroporation. Tomato heterologs whenever applicable were initially used in the VIGS screening because the corresponding expressed sequence tags (EST) were not available in the $N$. benthamiana EST library at the time the experiments were initiated. The use of heterologous genes from tomato (Solanum lycopersicum) and other solanaceae members for gene silencing in $N$. benthamiana and vice versa by VIGS is well-documented (Ekengren et al. 2003; Kang et al. 2004; Ryu et al. 2004).

\section{Construction of a cDNA library in a TRV vector.}

A cNbME library was made with $N$. benthamiana leaf tissue treated with abiotic and biotic elicitors, cloned into a TRVbased vector and transformed into GV2260, as described by del Pozo and associates (2004).

\section{VIGS.}

Agroinoculations for VIGS were done either by the toothpick method (for fast-forward genetics) or by using the leaf infiltration method (for reverse genetics) described by Ryu and associates (2004) with minor modifications. Clones from 96-well plates containing $p T R V 2$ derivative plasmids (containing the cDNA library) were stamped on solid LB agar medium and grown overnight at $30^{\circ} \mathrm{C}$. For the toothpick method, A. tumefaciens GV2260 containing pTRV1 was grown overnight (optical density at $\left.600 \mathrm{~nm}\left(\mathrm{OD}_{600}\right)=1\right)$ and was infiltrated into the lower leaves of $N$. benthamiana plants at the four-leaf stage using a 1$\mathrm{ml}$ syringe, whereas the individual $p T R V 2$ derivative cDNA clones were directly picked (with a toothpick) from 2-day-old LB plates and were pricked on the upper side of the $p T R V 1$ infiltrated region of the leaves. Plants were incubated in the greenhouse $\left(23 \pm 3^{\circ} \mathrm{C} ; 70 \%\right.$ humidity; 16-h photoperiod with supplemental lighting 50 to $100 \mu \mathrm{E} \mathrm{s}^{-1} \mathrm{~m}^{-2}$ ) for 14 to 18 days for silencing to occur. Two plants were inoculated with each clone during 
initial screening. In subsequent secondary and tertiary screenings, more than four plants were inoculated with each clone.

For reverse genetics, a leaf infiltration method of agroinoculation was used. A. tumefaciens GV2260 containing the $p T R V 1$ or $p T R V 2$ and their derivatives were cultured overnight at $28^{\circ} \mathrm{C}$ on liquid LB medium. Bacterial cells containing $p T R V 1-$ or pTRV2-derivated plasmids were harvested by centrifugation and were resuspended in double distilled water $\left(\mathrm{OD}_{600}=1\right)$, mixed at a 1:1 ratio, and were inoculated into the lower leaves of $N$. benthamiana plants at the four-leaf stage by leaf-infiltration (Liu et al. 2002b; Ryu et al. 2004).

We detected the transcript of the virus and the recombinant genes by RT-PCR, using the coat protein-specific primers 5'CTGGGTTACTAGCGGCACTGAATA-3' (forward primer) and 5'-TCCACCAAACTTAATCCCGAATAC-3' (reverse primer) and the GATEWAY vector-specific primers in the transiently silenced plants of $N$. benthamiana 2 weeks after inoculation. A minimum of 10 replications were performed for each experiment and the experiment was repeated at least three times.

\section{In planta tumor assay.}

For reverse genetic screening, shoots of the gene-silenced plants and empty vector control plants (TRV::00) were inoculated by slightly injuring the stem, using a needle with suspension cultures of tumorigenic strain A. tumefaciens A348 containing the octopine type Ti plasmid (pTiA6) 3 weeks postsilencing. Tumors on shoots were scored after 4 weeks. For fast-forward screenings, the shoots of all the 1,000 plants in duplicates were inoculated with A348 14 days after virus inoculation for an in planta tumor assay as described above. The crown gall phenotypes were recorded 3 to 4 weeks after Agrobacterium inoculation and were scored based on visual observations as wild-type tumors, no tumors, mild tumors, and super tumors (Fig. 1A). Clones that, when silenced, showed an altered crown gall $(A C G)$ phenotype were rescreened at least twice with a minimum of three replicates per screening.

\section{Leaf-disk transformation assays.}

Leaf explants from the silenced and control plants were collected 3 weeks postsilencing and were washed twice with water, were treated with $10 \%$ Clorox for $10 \mathrm{~min}$, and were rinsed with sterile distilled water thrice before a cork borer $(0.5 \mathrm{~cm})$ was used to punch disks. The leaf disks were separately incubated with different Agrobacterium strains for $15 \mathrm{~min}$ and were blotted on sterile filter paper to remove excess bacteria, and they were later transferred to MS basal medium (4.32 g of MS minimal salts [Gibco-BRL, Gaithersberg, MD, U.S.A.] per liter, $1 \mathrm{ml}$ of vitamin stock solution $[0.5 \mathrm{mg} / \mathrm{ml}$ nicotinic acid, $0.5 \mathrm{mg} / \mathrm{ml}$ pyridoxine, and $0.5 \mathrm{mg} / \mathrm{ml}$ thiamine- $\mathrm{HCl}], 100 \mathrm{mg} / \mathrm{l}$ myo-inositol, $20 \mathrm{~g} /$ liter sucrose, and $1.8 \%$ phytagel) per liter and were cocultivated with the bacteria at $25^{\circ} \mathrm{C}$ for 2 days.

For leaf-disk tumorigenesis assay, we infected leaf disks with A. tumefaciens A348. Two days after cocultivation, approximately 15 to 20 leaf disks for each plant were transferred onto MS medium with $200 \mu \mathrm{g}$ of cefotaxamine per milliliter and $100 \mu \mathrm{g}$ of tricarcillin per milliliter to kill A. tumefaciens and were incubated for 4 weeks at $25^{\circ} \mathrm{C}$. Tumors produced per leaf disk were counted 3 weeks after infection. The total biomass of the leaf (including tumors) was measured by weighing the fresh and dry weights (incubated at $37^{\circ} \mathrm{C}$ for 5 days) of a minimum of 150 disks (five disks per treatment were pooled) in duplicate experiments.

For transient transformation assays, we infected the leaf disks with the nontumorigenic strain A. tumefaciens GV2260 containing the binary vector $p B I S N 1$ (Narasimhulu et al. 1996) or with the binary plasmid $p K M 1$ (Mysore et al. 1998) for promoterless gene expression analyses. After 2 days of cocultiva- tion, a few leaf disks (five to eight disks per silenced line) were washed with water, were blotted on filter paper, and were either immediately stained with X-gluc staining solution $(50$ $\mathrm{mM} \mathrm{NaH} \mathrm{PO}_{4}, 10 \mathrm{mM} \mathrm{Na}_{2}$ EDTA, $300 \mathrm{mM}$ mannitol, and 2 $\mathrm{mM} \mathrm{X}$-gluc, $\mathrm{pH} 7.0$, for 1 day at $37^{\circ} \mathrm{C}$ ) or were transferred onto CIM (4.32 g of MS minimal salts per liter, $1 \mathrm{ml}$ of vitamin stock per liter, $100 \mathrm{mg}$ of myo-inositol per liter, $20 \mathrm{~g}$ of glucose per liter, $0.5 \mathrm{mg}$ of 2,4-dichlorophenoxyacetic acid per liter, $0.3 \mathrm{mg}$ of kinetin per milliliter, $5 \mathrm{mg}$ of indole acetic acid per liter, and $1.8 \%$ phytagel containing $200 \mu \mathrm{g}$ of cefotaxamine per milliliter and $100 \mu \mathrm{g}$ of tricarcillin per milliliter). For GUS analyses, leaf disks were collected after 2, 4, 7, 10, 15, and 24 dpi. GUS activity was analyzed using fluorometric assays (Jefferson et al. 1987). Two different protein extracts were prepared by grinding five to eight leaf disks per silenced line in a microfuge tube containing GUS extraction buffer $(50 \mathrm{mM}$ $\mathrm{Na}_{2} \mathrm{HPO}_{4}, 5 \mathrm{mM}$ dithiothreitol, $1 \mathrm{mM} \mathrm{Na} \mathrm{N}_{2}$ EDTA, 0.1\% sarcosyl, $0.1 \%$ Triton $\mathrm{X}-100, \mathrm{pH} 7.0$ ), and two aliquots were assayed for each of the extracts to determine protein concentration and GUS activity, according to Jefferson and associates (1987). Protein concentrations of plant extracts were determined spectrophotometrically, using the Bio-Rad protein assay (Bio-Rad, Richmond, CA, U.S.A.) based on the Bradford method (Bradford 1976). Fluorescence of 4-methylumbelliferone was measured with a WALLAC 1420-11 multilabel counter (PerkinElmer Life Tech; Wallac OY, Turku, Finland).

For stable transformation assays, we inoculated leaf disks with the nontumorigenic strain A. tumefaciens GV2260 containing $p C A S 1$ (Nam et al. 1999). After 2 days, the leaf disks were transferred onto CIM $+5 \mu \mathrm{g}$ of glufosinate ammonium (GF) per milliliter and were incubated at $25^{\circ} \mathrm{C}$. We scored the number of leaf disks with GF-resistant calli 4 weeks after Agrobacterium infection.

\section{RNA extraction, RT-PCR, qRT-PCR and differential gene expression analyses.}

For differential gene expression analyses of $N b \alpha$-Exp upon infection with different $A$. tumefaciens strains, $N$. benthamiana plants were vacuum-infiltrated with an avirulent Agrobacterium strain (A136; nononcogenic, lacking a Ti plasmid), a TDNA transfer-competent Agrobacterium strain (At804; nononcogenic, containing $p B I S N 1$ with a Ti plasmid facilitating the transfer of T-DNA and Vir proteins) at a concentration of $1 \times$ $10^{7} \mathrm{CFU} / \mathrm{ml}$, or the infiltration buffer. Samples were collected at different timepoints after inoculation for semiquantitative RT-PCR (5'-GAACGACGACGGTGGGTGGTG-3' and 5'-CC ATCGTTGAACAATGCAGTACT-3') and qRT-PCR. The experiments were repeated two times.

\section{Agrobacterium attachment assay.}

For effective and stable ectopic expression of GFPuv in A. tumefaciens, the fragment corresponding to GFPuv was PCRamplified from $p G F P u v$ (ClonTech, Mountain View, CA, U.S.A.) and was cloned downstream of the constitutive $p s b A$ promoter and an efficient ribosome-binding site from $\mathrm{T} 7$ gene10 of pUTgfp resulting in the plasmid pDSK-GFPuv (K. Wang and K. S. Mysore, unpublished data). The plasmid was transferred into A. tumefaciens GV2260 or the $c h v B^{-}$attachment-deficient strain (Douglas et al. 1985) by triparental mating using $p R K 2013$ as a helper plasmid. For attachment assays, 10 to 15 aseptic leaf segments $(0.5-\mathrm{cm}$ diameter $)$ derived from the Nb $\alpha$-Exp-silenced plants, TRV::00, and wild-type $N$. benthamiana plants were cocultivated for $15 \mathrm{~min}$ at room temperature with different bacterial dilutions $\left(\mathrm{OD}_{600}\right.$ of approximately 0.1 corresponds to $1 \times 10^{8} \mathrm{CFU} / \mathrm{ml}$ ) in saline water $(0.9 \% \mathrm{NaCl})$. Excess bacterial cultures were blotted on sterile filter from the cut-leaf segments, and the leaf segments were 
transferred to MS basal medium (4.32 g of MS minimal salts per liter) and were continued to cocultivate with the bacteria. The leaf segments were sampled 2, 12, and 24 hpi and were washed gently three to four times with phosphate-saline buffer and were briefly vortexed at very low speed (20 to $30 \mathrm{rpm}$ ) for 5 to $10 \mathrm{~min}$. Fluorescent bacteria in leaf tissues were visualized along the cut surfaces using a Leica TCS SP2 AOBS confocal system (Leica Microsystems, Wetzlar, Germany). Image acquisitions were carried out using excitation at $488 \mathrm{~nm}$ and collecting emitted light from 500 to $600 \mathrm{~nm}$ with either a 20x dry objective (NA 0.7 ) or a $63 \times$ water immersion objective (NA 1.2). The experiments were repeated three times. For bacterial growth assays, the same number of leaf disks from the Nb $\alpha$-Exp-silenced plants and the TRV::00 plants that were inoculated with different bacterial dilutions of either the disarmed Agrobacterium sp. strain GV2260 or the $c h v B^{-}$attachment-deficient strain were collected at $24 \mathrm{hpi}$, were ground in $0.9 \% \mathrm{NaCl}$ solution, and serial dilutions were made and plated on LB media with appropriate antibiotics for counting CFU. The experiments were repeated three times.

\section{T-DNA integration assay.}

The T-DNA integration assays were performed as detailed by $\mathrm{Li}$ and associates (2005). Calli regenerating from leaf disks transformed with a binary vector harboring uidA gene on a nonselective media were collected from a pool of two independent experiments, were washed with dimethyl sulfoxide ( $15 \% \mathrm{vol} / \mathrm{wt})$ several times to remove attached A. tumefaciens, and DNA was extracted using DNAzol (Invitrogen). Semiquantitative PCR was performed using the following primer combinations: GUS primers 5'-CGATCAGTTCGCCGATGG-3' (forward) and 5'-TCCCGCTAGTGCCTTGTCC 3' (reverse) that encompasses the intron (Mysore et al. 1998) and bacterial chromosomal gene (Atu0792) primers 5'-GCGTTCGCTGGT GTCACGCC-3' and 5'-GATCAGCGGAGACCAGCTTC-3'. Duplicate samples were analyzed by qPCR (as detailed earlier) with the primers GUS-FP 5'-AGGTGCACGGGAATATTTCG$3^{\prime}$ and GUS-RP 5'-ACGCGTCGGGTCGAGTT-3', and the amount of integrated T-DNA in the calli derived from $\mathrm{H}_{3}$ silenced plants was calculated relative to the amount of integrated T-DNA for the calli derived from TRV::00-inoculated plants. As a loading control for silenced and nonsilenced plants, parallel reactions using $N$. benthamiana elongation factor $1-\alpha(N b E f 1 \alpha)$ primers were carried out.

\section{Data analysis.}

Data were subjected to analysis of variance using JMP software version 4.0.4 (SAS Institute Inc., Cary, NC, U.S.A.). When a significant $F$-test was obtained at $P=0.05$, separation of treatment means was accomplished by Fisher's protected least significant difference.

\section{ACKNOWLEDGMENTS}

We thank S. P. Dinesh-Kumar for providing GATEWAY ready TRV-VIGS vectors, S. Gelvin for many strains of A. tumefaciens, and M. Hartwell and C. Jones for their assistance with leaf-disk transformation assays. We thank E. Blancaflor for critically reading the manuscript. This work was funded by grants from the Noble Foundation and a National Science Foundation (NSF) award (IOB-0445799) to K. S. Mysore and by the NSF Plant Genome Program (DBI-0116076) to G. B. Martin. The Leica AOBS confocal system used in this study was purchased with an NSF equipment grant (DBI-0400580).

\section{LITERATURE CITED}

Anand, A., and Mysore, K. S. 2005. Current advances in Agrobacteriumplant interactions and their implications on agricultural biotechnology.
Pages 221-242 in: Advances in Plant Physiology Vol. 8. A. Hemantaranjan, ed. Scientific Publishers, Jodhpur, India.

Ballas, N., and Citovsky, V. 1997. Nuclear localization signal binding protein from Arabidopsis mediates nuclear import of Agrobacterium VirD2 protein. Proc. Natl. Acad. Sci. U.S.A. 94:10723-10728.

Baulcombe, D. C. 1999. Fast forward genetics based on virus-induced gene silencing. Curr. Opin. Plant Biol. 2:109-113.

Baulcombe, D. C. 2002. RNA silencing. Curr. Biol. 12:R82.

Bradford, M. M. 1976. A rapid and sensitive method for the quantitation of microgram quantities of protein utilizing the principle of protein-dye binding. Anal. Biochem. 72:248-254.

Bundock, P., den Dulk-Ras, A., Beijersbergen, A., and Hooykaas, P. J. J. 1995. Trans-kingdom T-DNA transfer from Agrobacterium tumefaciens to Saccharomyces cerevisiae. EMBO (Eur. Mol. Biol. Organ.) J. 14:3206-3214.

Burch-Smith, T. M., Anderson, J. C., Martin, G. B., and Dinesh-Kumar, S. P. 2004. Applications and advantages of virus-induced gene silencing for gene function studies in plants. Plant J. 39:734-746.

Cascales, E., and Christie, P. J. 2004. Definition of a bacterial type IV secretion pathway for a DNA substrate. Science 304:1170-1173.

Christie, P. J. 2004. Type IV secretion: The Agrobacterium VirB/D4 and related conjugation systems. Biochem. Biophys. Acta. 1694:219-234.

Cohn, J., Day, R. B., and Stacey, G. 1998. Legume nodule organogenesis. Trends Plant Sci. 3:105-110.

Constantin, G. D., Krath, B. N., MacFarlane, S. A., Nicolaisen, M. Johansen, I. E., and Lund, O. S. 2004. Virus-induced gene silencing as a tool for functional genomics in a legume species. Plant J. 40:622-631.

Cosgrove, D. J. 2000. Loosening of plant cell walls by expansins. Nature 407:321-326.

Cosgrove, D. J., Li, L. C., Cho, H.-T., Hoffmann-Benning, S., Moore, R C., and Blecker, D. 2002. The growing world of expansins. Plant Cell Physiol. 43:1436-1444.

de Groot, M. J., Bundock, P., Hooykaas, P. J. J, and Beijersbergen, A. G. 1998. Agrobacterium tumefaciens-mediated transformation of filamentous fungi. Nat. Biotechnol. 16:839-842.

del Pozo, O., Pedley, K. F. and Martin, G. B. 2004. MAPKKK $\alpha$ is a positive regulator of cell death associated with both plant immunity and disease. EMBO (Eur. Mol. Biol. Organ.) J. 23:3072-3082.

Denarie, J., Debelle, F., and Prome, J. C. 1996. Rhizobium lipo-chitooligosaccharide nodulation factors: Signaling molecules mediating recognition and morphogenesis. Ann. Rev. Biochem. 65:503-535.

Dinesh-Kumar, S. P., Anandalakshmi, R., Marathe, R., Schiff, M., and Liu, Y. 2003. Virus-induced gene silencing. Pages 287-293 in: Plant Functional Genomics. Vol. 236. E. Grotewold., ed. Humana Press, Totowa, NJ, U.S.A.

Ditt, R. F., Nester, E. W., and Comai, L. 2001. Plant gene expression response to Agrobacterium tumefaciens. Proc. Natl. Acad. Sci. U.S.A. 98:10954-10959.

Douglas, C. J., Staneloni, R. J., Rubin, R. A., and Nester, E. W. J 1985. Agrobacterium tumefaciens mutants affected in attachment to plant cells. J. Bacteriol. 161:850-860.

Ekengren, S. K., Liu, Y., Schiff, M., Dinesh-Kumar, S. P., and Martin, G. B. 2003. Two MAPK cascades, NPR1, and TGA transcription factors play a role in Pto-mediated disease resistance in tomato. Plant $\mathrm{J}$. 36:905-917.

Gaspar, Y. M., Nam, J., Schultz, C. J., Lee, L. -Y., Gilson, P.R., Gelvin, S.B., and Bacic A. 2004. Characterization of the Arabidopsis lysine-rich arabinogalactan-protein AtAG17 mutant (rat1) that results in a decreased efficiency of Agrobacterium transformation. Plant Physiol. 135:21662-22171.

Gelvin, S. B. 2000. Agrobacterium and plant genes involved in T-DNA transfer and integration. Annu. Rev. Plant Physiol. Plant Mol. Biol. 51:223-256.

Gelvin, S. B. 2003a. Agrobacterium-mediated plant transformation: The biology behind the "gene-jockeying" tool. Microbiol. Mol. Biol. Rev. 67:16-37

Gelvin, S. B. 2003b. Improving plant genetic engineering by manipulating the host. Trends Biotechol. 21:95-98.

Jefferson, R. A., Kavanagh, T. A., and Bevan, M. W. 1987. GUS fusions: $\beta$-glucuronidase as a sensitive and versatile gene fusion marker in higher plants. EMBO (Eur. Mol. Biol. Organ.) J. 6:901-907.

Kang, L., Tang, X., and Mysore, K. S. 2004. Pseudomonas type III effector AvrPto suppresses the programmed cell death induced by two nonhost pathogens in Nicotiana benthamiana and tomato. Mol. PlantMicrobe Interact. 17:1328-1336.

Kelly, B. A., and Kado, C. I. 2002. Agrobacterium-mediated T-DNA transfer and integration into the chromosome of Streptomyces lividans. Mol. Plant Pathol. 3:125-134.

Kunik, T., Tzfira, T., Kapulnik, Y., Gafni, Y., Dingwall, C., and Citovsky V. 2001. Genetic transformation of HeLa cells by Agrobacterium. Proc. 
Natl. Acad. Sci. U.S.A. 98:1871-1876.

Lacroix, B., Vaidya, M., Tzfira, T., and Citovsky V. 2005. The VirE3 protein of Agrobacterium mimics a host cell function required for plant genetic transformation. EMBO (Eur. Mol. Biol. Organ.) J. 24:428-437.

Lee, Y., Choi, D., and Kende, H. 2001. Expansins: Ever-expanding numbers and functions. Curr. Opin. Plant. Biol. 4:527-532.

Li, J., Vaidya, M., White, C., Vainstein, A., Citovsky, V., and Tzfira T. 2005. Involvement of KU80 in T-DNA integration in plant cells. Proc. Natl. Acad. Sci. U.S.A. 102:19231-19236.

Liu, Y., Schiff, M., and Dinesh-Kumar, S. P. 2002a. Virus-induced gene silencing in tomato. Plant J. 31:777-786.

Liu, Y., Schiff, M., Marathe, R., and Dinesh-Kumar, S. P. 2002b. Tobacco Rar1, EDS1 and NPR1/NIMI1 like genes are required for $N$-mediated resistance to tobacco mosaic virus. Plant J. 30:415-429.

Liu, Y., Nakayama, N., Schiff, M., and Dinesh-Kumar, S. P. 2004a. Involvement of MEK1, MAPKK, NTF6, MAPK, WRKY/MYB transcription factors, $C O 11$ and $C T R 1$ in $N$-mediated resistance to tobacco mosaic virus. Plant J. 38:800-809.

Liu, Y., Nakayama, N., Schiff, M., Litt, A., Irish, V. F., and Dinesh-Kumar, S. P. 2004b. Virus induced gene silencing of a DEFICIENS ortholog in Nicotiana benthamiana. Plant Mol. Biol. 54:701-711.

Liu, Z., Hong, S. -W., Escobar, M. A., Vierling, E., Mitchell, D. L., Mount, D. W., and Hall J. D. 2003. Arabidopsis UVH6, a homolog of human $X P D$ and yeast $R A D 3$ DNA repair genes, functions in DNA repair and is essential for plant growth. Plant Physiol. 132:1405-1414.

Lu, R., Malcuit, I., Moffett, P., Ruiz, M. T., Peart, J., Wu, A.-J., Rathjen, J. P., Bendahmane, A., Day, L., and Baulcombe, D. C. 2003a. High throughput virus-induced gene silencing implicates heat shock protein 90 in plant disease resistance. EMBO (Eur. Mol. Biol. Organ.) J. 22:5690-5699.

Lu, R., Martin-Hernandez, A. M., Peart, J. R., Malcuit, I., and Baulcombe, D. C. 2003b. Virus-induced gene silencing in plants. Methods 30:296-303.

Matthews, R. 1991. Plant Virology, 3rd ed. Academic Press, San Diego, CA, U.S.A.

Matthysse, A. G. 1987. Characterization of nonattaching mutants of Agrobacterium tumefaciens. J. Bacteriol. 169:313-323.

Mysore, K. S., Bassuner, B., Deng, X. B., Darbinian, N. S., Motchoulski, A., Ream, W., and Gelvin, S. B. 1998. Role of the Agrobacterium tumefaciens VirD2 protein in T-DNA transfer and integration. Mol. PlantMicrobe Interact. 11:668-683.

Mysore, K. S., Nam, J., and Gelvin, S. B. 2000. An Arabidopsis histone H2A mutant is deficient in Agrobacterium T-DNA integration. Proc. Natl. Acad. Sci. U.S.A. 97:948-953.

Nam, J., Matthysse, A. G., and Gelvin, S. B. 1997. Differences in susceptibility of Arabidopsis ecotypes to crown gall disease may result from a deficiency in T-DNA integration. Plant Cell 9:317-333.

Nam, J., Mysore, K. S., Zheng, C., Knue, M. K., Matthysse, A. G., and Gelvin, S. B. 1999. Identification of T-DNA tagged Arabidopsis mutants that are resistant to transformation by Agrobacterium. Mol. Gen. Genet. 261:429-438.

Narasimhulu, S., Deng, X.-B, Sarria, R., and Gelvin, S. B. 1996. Early transcription of Agrobacterium T-DNA genes in tobacco and maize. Plant Cell 8:873-886.

Piers, K. L., Heath, J. D., Liang, X., Stephens, K. M., and Nester, E. W. 1996. Agrobacterium tumefaciens-mediated transformation of yeast. Proc. Natl. Acad. Sci. U.S.A. 93:613-1618.

Rho, H. S., Kang, S., and Lee, Y. H. 2001. Agrobacterium tumefaciensmediated transformation of plant pathogenic fungus, Magnaporthe grisea. Mol. Cells 12:407-411.

Ruiz, M. T., Voinnet, O., and Baulcombe, D. C. 1998. Initiation and maintenance of virus-induced gene silencing. Plant Cell 10:937-946.

Ryu, C.-M., Anand, A., Kang, L., and Mysore, K. S. 2004. Agrodrench: A novel and effective agroinoculation method for virus-induced gene silencing in roots and diverse solanaceous species. Plant J. 40:322-331.

Sampedro, J., and Cosgrove, D. J. 2005. The Expansin superfamily. Genome Biol. 6:R242.
Schrammeijer, B., den Dulk-Ras, A., Vergunst, A. C., Jurado Jacome, E. and Hooykaas, P. J. J. 2003. Analysis of Vir protein translocation from Agrobacterium tumefaciens using Saccharomyces cerevisiae as a model: Evidence for transport of a novel effector proteinVirE3. Nucleic Acids Res. 31:860-868.

Schultze, M., and Kondorosi, A. 1998. Regulation of symbiotic root nodule development. Annu. Rev. Genet. 32:33-57.

Staiger, C. J. 2000. Signaling to the actin cytoskeleton in plants. Ann. Rev. Plant Physiol. Plant Mol. Biol. 51:257-288.

Stephens, D. J., and Banting, G. 2000. The use of yeast two-hybrid screens in studies of protein: Protein interactions involved in trafficking. Traffic 1:763-768.

Tzfira, T., and Citovsky, V. 2002. Partners-in-infection: Host proteins involved in the transformation of plant cells by Agrobacterium. Trends Cell Biol.12:21-129.

Tzfira, T., Vaidya, M., and Citovsky, V. 2001. VIP1, an Arabidopsis protein that interacts with Agrobacterium VirE2, is involved in VirE2 nuclear import and Agrobacterium infectivity. EMBO (Eur. Mol. Biol. Organ.) J. 20:3596-3607.

Tzfira, T., Vaidya, M., and Citovsky, V. 2004. Involvement of targeted proteolysis in plant genetic transformation by Agrobacterium. Nature 431:87-92.

van Attikum, H., Bundock, P., and Hooykaas, P. J. J. 2001. Non-homologous end-joining proteins are required for Agrobacterium T-DNA integration. EMBO (Eur. Mol. Biol. Organ.) J. 20:6550-6558.

Veena, S., Jiang, H., Doerge, R. W., and Gelvin, S. B. 2003. Transfer of TDNA and Vir proteins to plant cells by Agrobacterium tumefaciens induces expression of host genes involved in mediating transformation and suppresses host defense gene expression. Plant J. 35:219-226.

Vergunst, A. C., Schrammeijer, B., den Dulk-Ras, A., de Vlaam, C. M. T., Regensburg-Tuink, T. J., and Hooykaas P. J. J. 2000. VirB/D4-dependent protein translocation from Agrobacterium into plant cells. Science 290:979-982.

von Mering, C., Krause, R., Snel, B., Cornell, M., Oliver, S. G., Fields, S., and Bork, P. 2002. Comparative assessment of large-scale data sets of protein-protein interactions. Nature 417:399-403.

Wagner, V. T., and Matthysse, A. G. 1992. Involvement of a vitronectinlike protein in attachment of Agrobacterium tumefaciens to carrot suspension cells. J. Bacteriol. 174:5999-6003.

Wasteneys, G. O., and Galway, M. E. 2003. Remodeling the cytoskeleton for growth and form: And overview with some new views. Ann. Rev. Plant Biol. 54:691-722.

Waterhouse, P. M., Wang, M.-B., and Lough, T. 2001. Gene silencing as an adaptive defence against viruses. Nature 411:834-842.

Yi, H. C., Mysore, K. S., and Gelvin, S. B. 2002. Expression of the Arabidopsis histone $H 2 A-1$ gene correlates with susceptibility to Agrobacterium transformation. Plant J. 32:285-298.

Yi, H.C., Sardesai, N., Fujinuma, T., Chan, C.-W., Veena, S., and Gelvin, S.B. 2006. Constitutive expression exposes functional redundancy between the Arabidopsis Histone H2A Gene HTA1 and other H2A gene family members. Plant Cell 18:1575-1589.

Zhu, J., Oger, P. M., Schrammeijer, B, Hooykaas, P. J. J., Farrand, S. K., and Winans, S. C. 2000. The bases of crown gall tumorigenesis. J. Bacteriol. 182:3885-3895.

Zhu, Y., Nam, J., Mysore, K. S., Lee, L. -Y., Cao, H., Valentine, L., Li, J., Kaiser, A. D., Kopecky, A. L. Hwang, H. H., Bhattacharjee, S., Rao, P. K., Tzfira, T., Rajagopal, J., Yi, H., Veena, S., Yadav, B. S., Crane, Y. M., Lin, K., Larcher, Y., Gelvin, M. J., Knue, M., Ramos, C., Zhao, X., Davis, S. J., Kim, S. I., Ranjith-Kumar, C. T., Choi, Y. J., Hallan, V. K., Chattopadhyay, S., Sui, X., Ziemienowicz, A., Matthysse, A. G., Citovsky, V., Hohn, B., and Gelvin, S. B. 2003a. Identification of Arabidopsis rat mutants. Plant Physiol. 132:494-505.

Zhu, Y., Nam, J., Carpita, N. C., Matthysse, A. G., and Gelvin, S. B. 2003b. Agrobacterium-mediated root transformation is inhibited by mutation of an Arabidopsis cellulose synthase-like gene. Plant Physiol. 133:1000-1010. 